\title{
Neisseria Gonorrhoeae Infections: Biological Diagnosis, Antibiotic Resistance and Treatment
}

\section{Mohammd Sbiti*, Imane Benbella,Rabii Behraoui and lhoussaïn Louzi}

Medical Biology Laboratory Service, Moulay Ismail Military Hospital, Meknes, Morocco

*Corresponding Author: Mohammd Sbiti, Medical Biology Laboratory Service, Moulay Ismail Military Hospital, Meknes, Morocco.

Received: August 21, 2019; Published: October 15, 2019

DOI: 10.31080/ASMI.2019.02.0397

\begin{abstract}
Neisseria gonorrhoeae is a Gram-negative diplococcus in coffee beans, specific to the human genital tract. This bacterium is, along with Chlamydiae trachomatis, one of the main germs responsible for sexually transmitted infections in the world. Infection with Neisseria gonorrhoeae is associated with a wide range of noisier clinical manifestations in humans. It is also responsible for several complications and sequelae affecting the reproductive pathways, especially in women. In recent years, the incidence of Neisseria gonorrohoae infections has increased, as has its resistance profile to the different classes of antibiotics available.

Hence the interest in presenting an overview of the literature's data on microbiological diagnosis of Neisseria gonorrohae and its various pathogenic mechanisms as well as antibiotic resistance mechanisms.
\end{abstract}

Keywords: Neisseria Gonorrhoeae; Chlamydiae Trachomatis

\section{Introduction}

Neisseria gonorrhoeae (gonococcus) is a bacterium in the form of gram-negative and strict aerobic diplococcus. This very fragile pathogen is specific to the mucous membranes of the human genital tract. Its transmission is essentially through direct sexual transmission [1]. In addition, Neisseria gonorrhoeae is, along with chlamydiae trachomatis, one of the maingerms responsible for sexually transmitted infections worldwide [2.3]. While the symptomatology generated in men is often noisy, it is in more than $50 \%$ of cases mute in women promoting dissemination and at the same time constituting a major reservoir of infection [4].

Over the past decade, the incidence of Neisseria gonorrhoeae infection has increased, particularly among the young population [5]. According to the World Health Organization (WHO), the incidence of gonococcal disease has increased by $21 \%$ since 2005 and estimates 78 million new cases of gonorrhea per year. Estimates of prevalence and incidence varied by region and gender [6]. In Africa, the incidence of Gonococcal infection in symptomatic subjects was estimated at 8.2 million new cases per year. In Morocco, gonococcal disease is responsible for $62.8 \%$ of urethral discharges, making it the most common cause of sexually transmitted infections [7]. For example, infections with Neisseria gonorroheae, or gonococcal disease, are a public health problem, both in their high morbidity and in their socio-economic impact [6]. In addition, the emergence of resistance to multiple classes of antibiotics (penicillins, tetracyclines, fluoroquinolones and currently third-generation cephalosporins) represents a obstacle to controlling this infection $[8.9,10]$. Bacteriological diagnosis is based on conventional identification methods namely direct examination after Gram coloring, culture on special environments associated with the study of antibiotic sensitivity, and more recently techniques gene amplification [11].

\section{Pathophysiology}

N. gonorrhoeae is a mandatory human pathogen, as its pathogenic progress (transmission, adhesion, colonization and invasion), the bacterium expresses many virulence factors to promote survival and replication while remaining invasive and able to avoid immune responses to promote replication and survival. 
G onococcus's adhesion, survival and multiplication capabilities have been attributed to some of its elements that appear to be involved in its virulence. Thus, Neisseria gonorrhoeae adheres to the microvillosities of epithelial cells thanks to its adhesines. Among them are mainly: porines, the main proteins of external membranes, the Opa proteins (opacity associated proteins)represented by $\mathrm{Opa}_{50}$ which adheres to heparin sulphate of proteoglycans (HSPGs) and $\mathrm{Opa}_{52}$ that attach specifically to CEACAMs (carcinoembryonic antigen related cell adhesion molecules ) and lipo-oligosaccharide (LOS), a major glycopeptide of the outer membrane of gonococcus $[12,14]$. Type IV pili are also found, which, thanks to the phenomena of "twintching" and glycosylation $[15,16,17]$, confer a form of motility on the bacterium and allow it to surface exploration and attachment to epithelial cells mainly at the level of different mucous membranes and strengthen the adhesion of the bacterium $[17,18]$. Neisseria gonorrhoeae endocyté within vacuoles multiplies, then is released by exocytosis into the connective tissue under epithelial and this after fusing with the basal membrane [19]. Several mechanisms allow Gonococcus to escape the immune response. Notably, the synthesis of IgA proteases that allows Neisseria gonorroheae to cliver these antibodies as well as the outer membrane that prevents the lytic action of lyzosyme [20.21]. In addition, lip oligosaccharides (LOS) are capable of producing toxic effects by stimulating the production of TNF (TumorNecrosis Factor) by macrophages at the sub-space causing damage to the mucous cells.

In women, the predominance of lactobacilli within the normal vaginal flora ensures the ecological balance of the vagina, notably by hydrolyzing glycogen in lactic acid which contributes to the acidification of the $\mathrm{pH}$ and by the secretion of hydrogen peroxide. inhibiting most pathogens including Neisseria gonorrhoeae. This explains the predisposition of women with unbalanced vaginal flora to develop gonococcal disease in the event of exposure. Furthermore, the presence of the supplement receptor (CR3) in the endocol and exocol may partly explain the asymptomatic form in women. Indeed, the endocytosis mediated by CR3 via the inactivated C3B on the surface of the gonococcus causes an internalization of the bacterium in the cells of the cervical epithelium and its elimination, without influx of neutrophils, therefore infection most often unnoticed. The absence of CR3 expression in human urethral epithelium contributes to the noisy nature of these infections [1,23]. Finally, it sit necessary to mention the difficulties encountered in the development of a specific vaccine against Neisseria gonorrhoeae; and which are related to the different surface modulations and one-off mutations experienced by its various surface antigens $[24,25]$.

Clinic

In men, genital gonococcal infection most often manifests itself in acute urethritis, which occurs after a contagious and silent incubation period of 2 to 7 days $[2,18]$. The symptomatology is noisy characterized by purulent urethral discharge, painful dysuria and intense urination burns [26,27]. Symptoms of inflammatory mastitis, or even balanitis, can also be found. Locoregional complications may occur. It is mainlyorchi-epidymite. In women, gonococcal infection is asymptomatic in $70-80 \%$ of cases. The most common manifestation is cervicitis. Anamnesis may find a notion of purulent leukorrhea, pelvic gravity and/or associated signs of urethritis. Examination most often shows a non- or little-inflammatory cervix with a purulent flow to the cervical opening [2]. Complications are more numerous than in humans: endometritis, salpingitis, tubo-ovarianabscess and pelvic peritonitis with reproductive sequelae in lack of treatment, (infertility, ectopic pregnancy, pelvic pain) $[28,29]$. In both sexes, infectious outbreaks can be found in extra genital, including anal, pharyngeal and conjunctival. Scattered forms can also be observed especially in women in the form of sepsis, eye damage or even other locations (articular, skin, heart, meningea) [27,30].

\section{Biological diagnosis}

The diagnosis of Infections with Neisseria gonorrhoeae relies primarily on direct methods (direct examination, culture, molecular biology), which are based on the detection of gonococci or their genomes in the various sites accessible for sampling (urethra, cervix, vagina, rectum, pharynx, and urine).

Taking

The latter, more or less invasive, differs according to sex, symptomatology, location and techniques used as summarized in table $1[2,32,33]$. It is important that the sample is taken before any antibiotic therapy and according to anoptimal procedure, in order to improve the reliability of the diagnosis. Thus, the experienced practitioner should be attentive to certain principles when taking the sample; these are summarized in table 2 [34]. Gonococcus is a fragile bacterium that tends to self-lying and does not survive desiccation and temperature variations. Therefore, the use of a suit- 
able environment when transporting samples seemed necessary (e.g. Vandekerkovemedium) [35].

\begin{tabular}{|c|c|}
\hline Clinical form & Types of samples \\
\hline $\begin{array}{l}\text { Vaginal attack Scree- } \\
\text { ning in women }\end{array}$ & Vaginal swab Auto-vaginal swab \\
\hline $\begin{array}{l}\text { Suspicion of endocer- } \\
\text { vicitis }\end{array}$ & $\begin{array}{l}\text { Removal of the endocol bysecramage - } \\
\text { collection of urine (first jet) }\end{array}$ \\
\hline $\begin{array}{l}\text { Suspicion of urethri- } \\
\text { tis in humans }\end{array}$ & $\begin{array}{l}\text { Remote urethral sampling of a urina- } \\
\text { tion with two dacron swabs (direct } \\
\text { examination/culture) after cleaning the } \\
\text { pipe-/- collection of urine (first spray) }\end{array}$ \\
\hline $\begin{array}{l}\text { Suspicion of an } \\
\text { ano-rectal location }\end{array}$ & $\begin{array}{l}\text { Ano-rectal sampling after cleaning the } \\
\text { anal opening }\end{array}$ \\
\hline Other locations & $\begin{array}{l}\text { Pharyngeal, ocular, skin, joint fluid, } \\
\text { hemocultures. }\end{array}$ \\
\hline
\end{tabular}

Table 1: Different Types of Samples Taken by Location and Sex NF,QBDN,IGH $[2.32,333]$.

\begin{tabular}{|l|l|}
\hline Prélèvement & Msures to take \\
\hline Urine sample & $\begin{array}{l}\text { Warning: Gene amplification diagnosis based } \\
\text { on a urine sample is less sensitive in women } \\
\text { than a cervical or vaginal smear. }\end{array}$ \\
$\begin{array}{l}\text { Sample collection at least one hour after last } \\
\text { urination }\end{array}$ & $\begin{array}{l}\text { Take the first urine stream (unlike the test for } \\
\text { the diagnosis of urinary tract infection, for } \\
\text { which medium-jet urine is more appropriate). } \\
\text { In practical terms: the patient must collect the } \\
\text { first drops of urine and fill the container up to a } \\
\text { maximum of 20 ml. }\end{array}$ \\
\hline $\begin{array}{l}\text { Cervical } \\
\text { smear }\end{array}$ & $\begin{array}{l}\text { Before sampling, remove any cervical secre- } \\
\text { tions with a large swab. Insert the swab into } \\
\text { the cervix sufficiently (1-2cm) and rub the } \\
\text { cervical wall in a rotating motion (at least } 2 \\
\text { rotations). Avoid contact with the vaginal wall } \\
\text { when removing the swab }\end{array}$ \\
\hline $\begin{array}{l}\text { Apply sufficient pressure when taking } \\
\text { smears }\end{array}$ & $\begin{array}{l}\text { Carefully remove: not only rub the posterior } \\
\text { wall of the pharynx but also the two tonsils }\end{array}$ \\
\hline $\begin{array}{l}\text { Do not use lubricant or local anesthesia. Insert } \\
\text { the swab sufficiently in a rotating motion } \\
\text { pressing lightly, rub the wall for 30 seconds to } \\
\text { promote the absorption of gonococcus in the } \\
\text { swab. }\end{array}$ \\
\hline smear
\end{tabular}

Table 2: Steps to Take for An Opitmal Sample to Diagnose Gonorrhea [34] (GNR).

\section{Direct review}

It is made on a spread of urethral flow, colored with Gram or failing methylene blue [28]. Gram-negative diplococs are set in intracellular "coffee beans"(Figure 1). This test has a sensitivity and specificity greater than $95 \%$ in cases of symptomatic male urethritis. However, it is more difficult in women vaginal or endocervical secretions of up to $65 \%$ as well as on other types of pre-lifts (pharynx, rectum). Therefore, a confirmation by culture is required $[2,28.36,37]$.

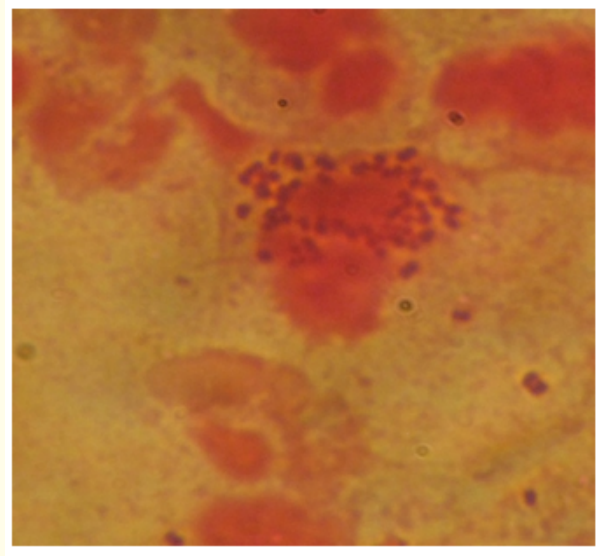

Figure 1: Neisseria gonorrhoeae present in gram coloring in a patient with gonococcal urethritis.

\section{Isolation and identification}

The cultivation of Neisseria gonorrhoae is difficult, due to its fragility, and these multiple metabolic requirements [5,37]. Thus, in addition to the need for an optimal growth temperature of 36 $-37^{\circ} \mathrm{C}$ and a moist atmosphere enriched with $\mathrm{CO}_{2}(5-10 \%)$, its cultivation requires a cooked blood agar or supplemented "chocolate agar" (hemine, blood or starch) to avoid the toxicity of fatty acids in agar [38]. In addition, other compounds will need to be added after sterilization including iron and cupteine (Polyvitex, glucose supplement), as well as antibiotics (Vancomycin, C olimycin, nyastatin,andother antifungal agents)to inhibit the growth of certain bacteria that can hinder the growthof Neisseria gonorrhoeae [39].

The orientation of bacteriological diagnosis must be accompanied by a macroscopic examination of the colonies; which appear in 18 - 48 hours, greyish, smooth, with regular edges, $0.5-1 \mathrm{~mm}$ in diameter; followed by confirmation by microscopic examination $[38,40]$. Colonies are positive oxidation, positive catalase. The different biochemical characteristics of gonococcus, including the absence of maltose oxidation, are defined when identified on Api $\mathrm{NH}$ galleries [40]. Culture is the standard gold for diagnosing Infection 
with Neisseria gonorrhoeae. Indeed, in addition to bacteriological identification, it is the only method to test the susceptibility of strains to antibiotics. It also allows, to carry out complementary tests such as serotyping and genotyping essential for epidemiological follow-up [5,40]. Moreover, it has a sensitivity approaching $90 \%$ and a specificity of almost $100 \%$ for the removals of the urethra and cervix. However, there are some drawbacks to cultivation, including the need to keep microorganisms viable, the difficulty of growing certain samples, and the time to obtain results $[41,1]$.

\section{Molecular biology}

Molecular biology methods detect nucleic acids in the bacterial genome by direct molecular hybridization using DNA probe or after in vitro amplification (NAATs- Nucleic Acid Amplification Tests) [5]. Currently, existing gene amplification techniques, known as second generation, are more specific than this first-generation lles. Indeed, the latter were the object of cross-reaction with the Commensales Neisseria, responsible of false positives [41]. These improved techniques have, as a result, become more sensitive and more suited to the series compared to the culture. They are also suitable for all sampling sites including the first urine jets and vaginal self-samples. Most NAATs on the market are called "multiplex", allowing early diagnosis by simultaneous evidence of Chlamydiae trachomatis and Neisseria gonorrhoeae, or more than two sexually transmitted infection agents $[42,43]$. However, the gene amplification technique only provides the diagnosis of gonorrhea. Thus, it seemed necessary to clarify that only the culture supplemented by the realization of an antibiotic bigram allows the identification of antibiotic resistance, and at the same time, the rectification of an inadequate treatment [11].

\section{Antibiotic sensitivity}

The minimum inhibitory concentrations (MICs) of the different antibiotics can be measured in the laboratory for clinical strains, if they could be isolated [11]. Antibiotics currently recommended by the French Microbiology Biopath Antibiotic Committee CA-SFM/ EUCAST in the standard list for Neisseria's antibiotic gonorrhoeae are penicillin G, cfixime, ceftriaxone, spectinomycin, has azithromycin and ciprofloxacin. The additional list includes chloramphenicol and tetracyclines [45]. The method of diffusion on cooked blood agar (plusvitamin supplements) using discs loaded with antibiotics gives random results with, in particular, a great difficulty in differentiating fully sensitive strains from intermediate sensitivity strains for many families of antibiotics [46]. In case of insuffi- cient growth after 24 hours, extend the incubation by an additional 20 hours. The production of beta-lactamase must be detected by a chromogenic technique as soon as it is isolated. It confers resistance to penicillin G, amino-, carboxyethyl ureido-penicillin's. The determination of MICs by the agar dilution method remains the reference method, with the detection of reduced sensitivity to penicillin's will be performed routinely by determining the CMI of penicillin G (CMI - 0.06mg/L). Indeed, it also makes it possible to carry out a routine evaluation of The CMI for the main molecules usedin therapeutics (ceftriaxone: CMI - 0.125mg/L, Cefixime: CMI - 0. 125 $\mathrm{mg} / \mathrm{L}$ and ciprofloxacin: $0.03 \mathrm{mg} / \mathrm{L}$ ). The decrease in sensitivity to 3rd generation cephalosporins is best detected with cefixime $[45,46]$.

\section{Antibiotic resistance}

Natural antibiotic resistance of Neisseria gonorrhoeae

Neisseria gonorrhoeae is a species naturally resistant to trimethoprim, colistin, and glycopeptides. These natural resistances are used to define antibiotic supplements used in selective settings.

\section{Evolution of acquired resistance}

Sulfonamides were one of the first classes of antibiotics to be widely used in the treatment of Neisseria gonorrhoeae infections, although this was for a short time, given the rapid onset of resistance [47]. During the 1940s, penicillin became the mainstay of gonococcal treatment. However, an increase in minimal inhibitory concentrations of penicillin and cyclins (considered a therapeutic alternative) to Neisseria gonorrhoeae caused their prescription to be discontinued in the late 1980s. This period also saw the advent of third-generation cephalosporins and quinolones as the main molecules prescribed in the treatment of gonococcal disease. The latter rapidly developed resistance [49]. Third-generation cephalosporins then became first-line antibiotics. Nevertheless, a decrease in sensitivity to cephalosporins has begun to appear among the strains of Neisseria gonorrhoeae. Between 1999 and 2002, the percentage of Neisseria gonorrhoeae isolates with a minimum cefixime inhibitor concentration of $0.5 \mathrm{~g} / \mathrm{ml}$ or more increased from $0 \%$ to $30 \%$ in Japan [47]. Other documented cases have been reported in Hong Kong and South Korea [50,51]. In July 2011, Ohnishi., et al. reported the case of a strain of Neisseria gonorrhoeae H041, isolated at the pharyngeal level in a prostitute, wearing a new PenA mosaic allele, which confers resistance to ceftriaxone and cefixime with MiCs 8 to 16 times more than the usual MICs (between 2-4g/ $\mathrm{ml}$ ) [11]. 
Clinical responses correlated with the decrease in cephalosporin SJCs are still little known. Nevertheless, therapeutic failures of cefixime in people infected with less sensitive Neisseria gonorrhoeae isolates have been reported. The first failure appeared in Japan 2003, in patients treated with multiple doses of cefixime 200 mg against Neisseria gonorrhoeae isolates with CMIs of $0.125 \mathrm{~g} / \mathrm{l}$ $-1 \mathrm{~g} / \mathrm{l}$. The response of the Japanese authorities was swift with a transition to ceftriaxone as the first line of treatment in 2006. In 2010, the first two cases of cefixime resistance in Europe were reported in two heterosexual Norwegian men. Both had presented a therapeutic failure in the face of $400 \mathrm{mg}$ doses of cefixime, but responded well when administering a $500 \mathrm{mg}$ dose of intramuscular ceftriaxone [52]. There is currently no clear evidence of clinical resistance to ceftriaxone, although it is to be feared given the increase in minimal inhibitory concentrations [11].

In Canada, Neisseria gonorrhoeae's aazithmycin resistance is an established fact and it spreads above 5\% [52]. Inthe United Kingdom, the spread of a clone of high-level azithromycin-resistant Neisseria gonorrhoeae [53].

\section{Resistance mechanisms}

The acquired resistances of Neisseria gonorrhoeae follow the accumulation of chromosomal mutations or genetic transfers. The acquisition of nude DNA is fostered by the natural processing capacity of this species. Genetic material from other strains of Neisseria gonorrhoeae or strains of bacterial commensal flora can be integrated by homologous recombination into the chromosome of Neisseria gonorrhoeae. This mechanism mainly concerns changes in the penicillin binding protein gene at which fragments of exogenous DNA have been integrated, creating real mosaic genes encoding penicillin binding proteins. decreased affinity for penicillin's. The acquisition of TEM1 penicillinase of plasmid origin has also been described [55]. Cyclone resistance is related to the transfer of the tetM gene, initially described in streptococci and carried by a transposon located at Neisseria gonorroheae on large plasmids conjugative [56]. The protein tetM encoded by the tetM gene protects the ribosomal target from the action of the cyclones. Chromosomal resistances were also implicated. They are related to alteration of major pi porin, hyperexpression of the Mtr CDE efflux pump, or changes in targets, such as the mutation of the rps] gene encoding ribosomal protein S10 [47]. For quinolones, single or combined mutations of genes encoding type II topoisomerases plays a major role in resistance. Notably, those of the gyrA gene encoding subunit A of gyrase DNA (theS91 and D95 mutations), and then the Gene byC encoding for subunit $\mathrm{C}$ topoisomerase IV. The hyperexpression of the Mtr CDE efflux system plays only an incidental role $[47,57,58]$. Decreased sensitivity to third-generation cephalosporins involves several mechanisms, including :47:

- $\quad$ Mutations in penA, penC, ponA genes, responsible for alteration of penicillin-binding proteins (PBP1 and/or PBP2)

- Mutations in the penB gene responsible for a major PI porin modification

- Hyperexpression of the MtrC-MtrD-MtrE efflux system, related to mutations in the mtrRD codant genea mtr CDE operon repressor or mutations in the mtrR promoter

For macrolides, it was found that the number of alleles of the 23S gene of RNA with mutations C2611T or A2059G was strongly correlated with resistance to azithromycin and mutation at the position of the amino acid G45 in the MtrR protein independently predicts resistance to azithromycin [57].

\section{Treatment}

Ideally the recommended therapeutic regimen, on the front line, should be able to treat $95 \%$ of infections with Neisseria gonorrhoeae. Furthermore, the recommended antibiotic therapy, should be highly effective, widely available, and affordable in quantity and in appropriate dose, it should also be devoid of toxic effect, with the possibility of single dose administration. Other criteria, such as prevalence, local epidemiology, frequency of transmission, treatment strategy, cost and diagnostic tests, should be considered in the event of a decision to modify the recommended treatment $[62,63]$. In response to the increase in antibiotic resistance experienced by Neisseria gonorrhoeae, it has been recommended to use a combination of antibiotics. The choice of molecules varies by population and site of infection (Table 3) [61.62]. New forms of biotherapy have also been evaluated for the treatment of uncomplicated forms of urogenital gonococcal disease. These are $240 \mathrm{mg}$ gentamicin in single intramuscular (IM) and azithromycin $2 \mathrm{~g}$ in single oral intake (PO), and 320mg single-take oral and azithromy$\operatorname{cin} 2 \mathrm{~g}$ in single-oral [63]. The cure rate was $100 \%$ for the combination gentamicin and azithromycin and $99.5 \%$ for Gemifloxacin and azithromycin. However, side effects, mainly gastrointestinal, have been frequently observed. Nevertheless, these two treatment regimens can be considered as an alternative in the event of failure of conventional treatment or in the presence of strains of resistance to cephalosporin [64]. In recent years, the activity of several an- 
tibiotic derivatives on strains of Neisseria gonorrhoeaehas been evaluated in vitro. Thus, the new Fluor ketolides azithromycin (macrolides) exhibits high activity against Neisseria gonorrhoeae, including ceftriaxone-resistant strains and multidrug-resistant strains. In addition, other molecules, such as solithromycin, Zoliflodacin, Gepotidacin and famulin, have also shown high activity on strains of Neisseria gonorrhoeae ceftriaxone. However, they are still in clinical trial $[65,66]$.

Alternative therapies to combat $N$. gonorrhoeae, which is becoming increasingly resistant, are being developed. These alterna- tives are mainly focused on preventing recurrent infections rather than on treatment such as intravaginalinterleukin-12 (IL-12), studies evaluated a new potential strategy or probiotics using strains of vaginal actobacillus (L. crispatus, L. gasseri and L. vaginalis) whose metabolism can reduce the viability of Mr. Gonococcus. Monocaprine and myristoleic acid is a promising ophthalmic prophylaxis to the antibacterial treatment of neonatal conjunctivitis. Another alternative treatment that has gained prominence recently is bacteriophage therapy, as a therapeutic option alone or associated with currently used antimicrobials [66,67].

\begin{tabular}{|c|c|c|}
\hline Guidelines & Infection anogénital* & Pharyngeal infection \\
\hline $\begin{array}{l}\text { Public Health } \\
\text { Agency of Canada: } \\
\text { Recommendations for } \\
\text { Gonorrhea Treatment }\end{array}$ & $\begin{array}{l}\text { Registered: } \\
\text { Ceftriaxone } 250 \mathrm{mg} \text { IM in single dose plus azi- } \\
\text { thromycin } 1 \text { g per bone in single dose } \\
\text { Cefixime } 800 \mathrm{mg} \text { PO in dose plus azithromycin } \\
1 \mathrm{~g} \text { POin singledose }\end{array}$ & $\begin{array}{l}\text { Registered: } \\
\text { •-Ceftriaxone } 250 \mathrm{mg} \text { IM en dose } \\
\text { unique as plus azithromycine } 1 \mathrm{~g} \text { per os } \\
\text { en dose unique }\end{array}$ \\
\hline 2016 [68] & $\begin{array}{l}\text { Alternatives: } \\
\text { •-Spectinomycine** } 2 \mathrm{~g} \text { IM en dose unique plus } \\
\text { azithromycin } 1 \mathrm{~g} \text { PO en dose unique } \\
\text { Azithromycin } 2 \mathrm{~g} \text { PO in single dose }\end{array}$ & $\begin{array}{l}\text { Alternatives: } \\
\text { Cefixime } 800 \text { mg PO in single dose } \\
\text { Plus azithromycine } 1 \mathrm{~g} \text { PO dose unique } \\
\text { •• Azithromycine } 2 \mathrm{~g} \text { PO dose unique }\end{array}$ \\
\hline $\begin{array}{l}\text { European Guidelines } \\
2012\end{array}$ & $\begin{array}{l}\text { Registered: } \\
\text { Ceftriaxone } 500 \mathrm{mg} \text { IM single dose plus azi- } \\
\text { thromycin } 2 \mathrm{~g} \text { PO in single dose }\end{array}$ & $\begin{array}{l}\text { Registered: } \\
\text { Ceftriaxone } 500 \mathrm{mg} \text { IM single dose plus } \\
\text { azithromycin } 2 \mathrm{~g} \text { PO in single dose }\end{array}$ \\
\hline & $\begin{array}{l}\text { Alternatives: } \\
\text { If ceftriaxone is not available or injection cannot } \\
\text { be administered } \\
\text { (Ex: patient refusal) - Cefixime } 400 \mathrm{mg} P 0 \text { in } \\
\text { single dose plus } \\
\text { azithromycin } 2 \mathrm{~g} \text { PO in single dose } \\
\text { If azithromycin is not available or patient unable } \\
\text { to swallow azithromycin: Ceftriaxone } 500 \text { mg in- } \\
\text { tramuscular in single dose } \\
\text { If there is a possibility or knowledge of resistance } \\
\text { or allergy to broad-spectrum cephalosporins: } \\
\text { Spectinomycin } 2 \text { g intramuscular in single dose } \\
\text { plus azithromycin } 2 \mathrm{~g} \text { PO in single dose. }\end{array}$ & $\begin{array}{l}\text { Alternatives: } \\
\text { If azithromycin is not available or pa- } \\
\text { tient unable to swallow azithromycin } \\
\text { Ceftriaxone } 500 \mathrm{mg} \text { IM en dose unique } \\
\text { If antecedents allergy to cephalos- } \\
\text { porins or penicillin (sevère) and if } N \text {. } \\
\text { gonorrhoeae is known } \\
\text { quinolone-sensible== } \\
\text { Ciprofloxacin } 500 \text { mg PO en dose } \\
\text { unique ou ofloxacin } 400 \text { mg PO en dose } \\
\text { unique } \\
\text { If an allergy antecedent (severe) to ce- } \\
\text { phalosporins or penicillin - Azithromy- } \\
\text { cin } 2 \text { g PO in single dose }\end{array}$ \\
\hline
\end{tabular}




\begin{tabular}{|c|c|c|}
\hline \multirow[t]{2}{*}{$\begin{array}{l}\text { UK National Guidelines } \\
\text { (BASHH) } 2015 \text { [69] }\end{array}$} & $\begin{array}{l}\text { Registered: } \\
\text { Ceftriaxone } 500 \mathrm{mg} \text { IM in single dose plus azi- } \\
\text { thromycin } 1 \mathrm{~g} \text { PO in single dose }\end{array}$ & \multirow{2}{*}{$\begin{array}{l}\text { Registered: } \\
\text { Ceftriaxone } 500 \mathrm{mg} \text { IM in single dose } \\
\text { plus azithromycin } 1 \mathrm{~g} \text { PO in single dose } \\
\text { If sensitive to quinolones: } \\
\text { Ciprofloxacin } 500 \mathrm{mg} \text { PO in single dose } \\
\text { or ofloxacin } 400 \mathrm{mg} \text { PO in dose. } \\
\text { Note: Spectinomycin has lower efficacy } \\
\text { in cases of pharyngeal infections. }\end{array}$} \\
\hline & $\begin{array}{l}\text { Alternatives (if IM vs. indicated, or patient refu- } \\
\text { sal): } \\
\text { Cefixime } 400 \mathrm{mg} \text { PO in single dose } \\
\text { Spectinomycin } 2 \mathrm{~g} \mathrm{IM} \text { in single dose } \\
\text {-.Cefotaxime } 500 \mathrm{mg} \text { IM en dose unique } \\
\text { If sensitive to quinolones: } \\
\text { Ciprofloxacin } 500 \mathrm{mg} \text { PO en dose unique ou } \\
\text { ofloxacine } 400 \mathrm{mg} \text { PO en dose unique } \\
\text { Azithromycin } 2 \mathrm{~g} \text { PO in single dose }\end{array}$ & \\
\hline
\end{tabular}

Table 3: Guidelines for Gonococcal Infection Treatments [65] (F). *site anogénital inclu: urethral, vaginal, rectal, et endocervical.

\section{Conclusion}

Infections with Neisseria gonorrhoeae, sexually transmitted infections, area public health problem both in its complications and in the growing emergence of multi-resistant strains. Moreover, the emergence of resistance to third-generation cephalosporins is particularly alarming in that they represent the last line of treatment, with no alternatives currently credible therapies. Therefore, the role of the biologist and clinician is necessary through sampling and diagnostic techniques management of gonococcus according to the various guides and algorithms evaluated. Similarly, a strategy to control sexually transmitted infections andto make sense of the concept of sexual health should be putin place for screening. effective treatment for patients and their partners.

\section{Bibliography}

1. Edwards JL. "The role of complement in gonococcal infection of cervical epithelia". Vaccine 26.8 (2008): I56-I61.

2. Cedef. "Maladies sexuellement transmissibles: infections urogénitales à gonocoque et Chlamydia trachomatis (en dehors de la maladie de Nicolas-Favre)". Annales de dermatologie et de vénérologie 139 (2012): A57-A61.

3. Boyadzhyan B., et al. "Comparaison of the APTIMA CT and GC assays with the APTIMA combo 2 assays, the Abbott LCx assay, and direct fluorescent antibody and culture assays for detection of Chlamydia trachomatis and Neisseria gonorrhoeae". Journal of Clinical Microbiology 42.7 (2004): 3089-3093.
4. Hughes G and Field N. "The epidemiology of sexually transmitted infections in the UK: impact of behavior, services and interventions". Future Microbiology 10.1 (2015): 35-51.

5. Haute Autorité de Santé Service evaluation économique et santé publique. "Dépistage et prise en charge de l'infection à Neisseria gonorrhoeae: état des lieux et propositions. (2010).

6. Newman L., et al. "Global Estimates of the Prevalence and Incidence of Four Curable Sexually Transmitted Infections in 2012 Based on Systematic Review and Global Reporting". PLoS One 10.12 (2015): e0143304.

7. Direction de l'Épidémiologie et de Lutte contre les Maladies (ministère de santé Maroc)". Programme National de Lutte contre les IST/SIDA. Rabat: DELM (2011).

8. Hook EW and Kirkcaldy RD. "A Brief History of Evolving Diagnostics and Therapy for Gonorrhea: Lessons Learned". Clinical Infectious Diseases 67.8 (2018):1294-1299.

9. Bodie M., et al. "Addressing the rising rates of gonorrhea and drug-resistant gonorrhea: There is no time like the present". Canada Communicable Disease Report 45.2-3 (2019): 54-62.

10. Ison CA. "Antimicrobial resistance in sexually transmitted infections in the developed world: implications for rational treatment". Current Opinion in Infectious Diseases 25.1 (2012):73-78.

11. Johan Chanal., et al. "Actualités diagnostique et thérapeutique des infections à Neisseria gonorrhoeae". La Presse Médicale 42 (2013):454-458. 
12. Quillin SJ and Seifert HS. "Neisseria gonorrhoeae host adaptation and pathogenesis". Nature Reviews Microbiology 16.4 (2018): 226-240.

13. Central PMCID: PMC6329377.

14. Nauciel Ch and Vildé J-L. "Bactériologie médicale". 2e edition". Paris, Masson. (2005): 257.

15. Edwards JL and Butler EK. "The pathobiology of Neisseria gonorrhoeae lower female genital tract infection". Frontiers in Microbiology 2 (2011): 102.

16. Henrichsen J. "Twitching Motility". Annual Review of Microbiology 37.1 (1983):81-93.

17. Mattick JS. "Type IV pili and twitching motility”. Annual Review of Microbiology 56.1 (2002): 289-314.

18. Ghosh SK., et al. "Pathogenic consequences of Neisseria gonorrhoeae pilin glycan variation". Microbes and Infection 6.7 (2004):693-701.

19. Scrivener $\mathrm{Y}$ and Cribier B. "Infections urogénitales à gonocoques et à Chlamydia (en dehors de la maladie de NicolasFavre): épidémiologie, diagnostic, évolution, traitement". Rev Prat 51.4 (2001): 453-458.

20. Woods CR. "Gonococcal infections in neonates and young children". Seminars in Pediatric Infectious Diseases 16.4 (2005): 258-270.

21. Cloud-Hansen KA., et al. "Neisseria gonorrhoeae uses two lytic transglycosylases to produce cytotoxic peptidoglycan monomers". Journal of Bacteriology 190.17 (2008): 5989-5994.

22. Nauciel C and Vildé JL. "Abrégés de Bactériologie médicale 2eme edition". Paris: Masson (2005).

23. E Bergogne-Bérézin. "Flores vaginales normales, vaginites et vaginoses bactériennes: diagnostic et thérapeutique". Antibiotiques 9.2 (2007): 139-144.

24. Edwards JL and Apicella MA. "The molecular mechanisms used by Neisseria gonorrhoeae to initiate infection differ between men and women". Clinical Microbiology Reviews 17.4 (2004): 965-981.

25. Zhu W., et al. "Vaccines for gonorrhea: can we rise to the challenge?". Frontiers in Microbiology 2 (2011): 124.
26. Virji M. "Pathogenic neisseriae: surface modulation, pathogenesis and infection control". Nature Reviews Microbiology 7.4 (2009): 274-286.

27. Mariam R Chacko., et al. "Efficacy of a Motivational Behavioral Intervention to Promote Chlamydia and Gonorrhea Screening in Young Women". Journal of Pediatric and Adolescent Gynecology 21.4 (2008): 187-193.

28. Chaine B., et al. "Infections à gonocoques : aspects actuels et prise en charge". Rev Prat. 60.4 (2010): 533-538.

29. Bignell C and Unemo M. "2012 European STI Guidelines Editorial Board. 2012 European guideline on the diagnosis and treatment of gonorrhoea in adults". International Journal of STD and AIDS 24.2 (2013): 85-92.

30. Peter A Leone. "Maladie inflammatoire pelvienne. Médecine Interne de Netter (second edition)”. Elsevier SAS. (2011): 860864.

31. Ghosn SH and Kibbi AG. "Cutaneous gonococcal infections". Clinics in Dermatology 22.6 (2004): 476-480.

32. Olshen E and Shrier LA. "Diagnostic tests for chlamydial and gonorrheal infections". Seminars in Pediatric Infectious Diseases 16.3 (2005): 192-198.

33. Institut national de santé publique du Québec, Association des médecins microbiologistes-infectiologues du Québec. Guide de pratique pour les analyses de laboratoires en lien avec les ITSS: Détection de Neisseria gonorrhoeae par culture (2014).

34. Quentin R and Verdon R. "Les infections génitales hautes: bases microbiologiques du diagnostic et du traitement". Journal de Gynécologie Obstétrique et Biologie de la Reproduction 41.8 (2012): 850-863.

35. Toutous Trellu L., et al. "Gonorrhée: nouvelles recommandations en matière de diagnostic et de traitement". Forum Médical Suisse 14.20 (2014): 407-409.

36. JeanFreney., et al. "Précis de bactériologie clinique 2eme édition ESKA (2007): 931-938.

37. Bignell $\mathrm{C}$ and Fitzgerald $\mathrm{M}$. "UK national guideline for the management of gonorrhoea in adults, 2011". International Journal of STD and AIDS 22.10 (2011): 541-547.

38. Carole Emile. "Examens bactériologiques des prélèvements vaginaux à visée diagnostique”. Option Bi 20.411 (2009):1921. 
39. Centers for Disease Control and Prevention. "Recommendations for the laboratory-based detection of Chlamydia trachomatis and Neisseria gonorrhoeae-2014". MMWR Recommendations and Reports 63.02 (2014):1-19.

40. Avril JL., et al. "Bactériologie Clinique". Paris, Ellipses, (2000): 74-106.

41. Ng LK and Martin IE. "The laboratory diagnosis of Neisseria gonorrhoeae". Canadian Journal of Infectious Diseases and Medical Microbiology 16.1 (2005): 15-25.

42. Cook RL., et al. "Systematic review: noninvasive testing for Chlamydia trachomatis and Neisseria gonorrhoeae". Annals of Internal Medicine 142.11 (2005): 914-925.

43. Tabrizi SN., et al. "Evaluation of six commercial nucleic acid amplification tests for detection of Neisseria gonorrhoeae and other Neisseria species". Journal of Clinical Microbiology 49.10 (2011): 3610-3615.

44. Sadiq ST., et al. "Rapid accurate point-of-care tests combining diagnostics and antimicrobial resistance prediction for Neisseria gonorrhoeae and Mycoplasma genitalium". Sexually Transmitted Infections 93.S4 (2017): S65-S68.

45. Whittles LK., et al. "Epidemiological Trends of Antibiotic Resistant Gonorrhoea in the United Kingdom". Antibiotics (Basel) 7.3 (2018): pii: E60.

46. The European Committee on Antimicrobial Susceptibility Testing (EUCAST). “Comité de l'antibiogramme de la Société Française de Microbiologie (CA-SFM)". Recommandations V2 (2019): 99-100.

47. Carannante A., et al. "Cefixime and ceftriaxone susceptibility of Neisseria gonorrhoeae in Italy from 2006 to 2010". Clinical Microbiology and Infection 18.6 (2012): 558-564.

48. Barbee LA and Dombrowski JC. "Control of Neisseria gonorrhoeae in the era of evolving antimicrobial resistance". Infectious Disease Clinics of North America 27.4 (2013):723-737.

49. Workowski KA., et al. "Emerging antimicrobial resistance in Neisseria gonorrhoeae: urgent need to strengthen prevention strategies". Annals of Internal Medicine 148.8 (2008): 606-613.

50. Kulkarni S., et al. "Mutations in the gyrA and parC genes of quinolone-resistant Neisseria gonorrhoeae isolates in India". International Journal of Antimicrobial Agents 40.6 (2012): 549-553.
51. Lo JY., et al. "Ceftibuten resistance and treatment failure of Neisseria gonorrhoeae infection". Antimicrobial Agents and Chemotherapy 52.10 (2008): 3564-3567.

52. Lee H., et al. "Trends in antimicrobial resistance of Neisseria gonorrhoeae isolated from Korean patients from 2000 to 2006". Sexually Transmitted Diseases 38.11 (2011):1082-1086.

53. Unemo M., et al. "Two cases of verified clinical failures using internationally recommended first-line cefixime for gonorrhoea treatment, Norway, 2010". Eurosurveillance 15.47 (2010): pii: 19721.

54. Martin I., et al. "Neisseria gonorrhoeae, bactérie multirésistante et ultrarésistante, Canada, de 2012 à 2016". Relevé Des Maladies Transmissibles Au Canada 45.2-3 (2019) :48-55.

55. MacFadden DR., et al. "Multidrug-resistant Neisseria gonorrhoeae: implications for future treatment strategies". The Lancet Infectious Diseases 18.6 (2018): 599.

56. Dillon JA and Yeung KH. "Beta-lactamase plasmids and chromosomally mediated antibiotic resistance in pathogenic Neisseria species". Clinical Microbiology Reviews 2 (1989): S125S133.

57. Gascoyne DM., et al. "Molecular evolution of tetracycline-resistance plasmids carrying TetM found in Neisseria gonorrhoeae from different countries". Journal of Antimicrobial Chemotherapy 28.2 (1991):173-183.

58. Hall CL., et al. "Genotypic determinants of fluoroquinolone and macrolide resistance in Neisseria gonorrhoeae". Sex Health (2019).

59. Tanaka M., et al. "Susceptibilities of Neisseria gonorrhoeae isolates containing amino acid substitutions in GyrA, with or without substitutions in ParC, to newer fluoroquinolones and other antibiotics". Antimicrobial Agents and Chemotherapy 44 (2000): 192-195.

60. Ison CA., et al. "Current and future treatment options for gonorrhoea". Sexually Transmitted Infections 89.4 (2013): iv52iv56.

61. Roy K., et al. "Optimizing treatment of antimicrobial-resistant Neisseria gonorrhoeae”. Emerging Infectious Diseases 11.8 (2005):1265-1273.

62. Pogany L., et al. "Management of gonococcal infection among adults and youth: New key recommendations". Canadian Family Physician 61.10 (2015): 869-873 e451-e456. 
63. Piszczek J., et al. "Gonorrhea: Treatment update for an increasingly resistant organism". Canadian Pharmacists Journal (Ott). 148.2 (2015): 82-89.

64. Kirkcaldy RD., et al. "The efficacy and safety of gentamicin plus azithromycin and gemifloxacin plus azithromycin as treatment of uncomplicated gonorrhoea". Clinical Infectious Diseases 59.8 (2014):1083-1091.

65. Unemo M. "Current and future antimicrobial treatment of gonorrhoea - therapidly evolving Neisseria gonorrhoeae continues to challenge". BMC Infectious Diseases 15 (2015): 364.

66. Unemo M and Shafer WM. "Future treatment of gonorrhea-novel emerging drugs are essential and in progress?". Expert Opinion on Emerging Drugs 20.3 (2015): 357-360.

67. Suay-García B and Pérez-Gracia MT. "Future Prospects for Neisseria gonorrhoeae Treatment". Antibiotics (Basel). 7.2 (2018). pii: E49.

68. Churchward CP., et al. "Mutations in Neisseria gonorrhoeae grown in sub-lethalconcentrations of monocaprin do not confer resistance". PLoS One 13.4 (2018): e0195453.

69. Public Health Agency of Canada. Canadian Guidelines on Sexually Transmitted Infections (2019).

70. Centers for Disease Control and Prevention (CDC). Sexually Transmitted Diseases Treatment Guidelines (2019).

Volume 2 Issue 11 November 2019

(C) All rights are reserved by Mohammd Sbiti., et al.

Citation: Mohammd Sbiti, et al. "Neisseria Gonorrhoeae Infections: Biological Diagnosis, Antibiotic Resistance and Treatment". Acta Scientific

Microbiology 2.11 (2019): 41-50. 